\title{
Matriz Termofixa Fenólica em Compósitos Reforçados com Fibras de Bagaço de Cana-de-Açúcar
}

\author{
Jane Maria F. de Paiva e Elisabete Frollini
}

Resumo: Neste trabalho, a lignina extraída pelo processo organossolve do bagaço de cana-de-açúcar substituiu parcialmente fenol ( $40 \%$ em massa) em matrizes termofixas reforçadas com fibras curtas de bagaço de cana-de-açúcar $(30,40,50,60$ e 70\%, v/v). Os compósitos obtidos foram caracterizados por TG, DSC, DMTA, Resistência ao Impacto Charpy, Dureza Shore D. Os resultados obtidos mostraram ser viável a substituição de fenol por lignina em matrizes fenólicas. No entanto, para que se obtenha compósitos com propriedades compatíveis com às exigidas para aplicações industriais, modificações devem ser feitas: modificação de fibras por meio de reações químicas, diversificação do comprimento das fibras vegetais, realização de etapas de cura em temperaturas superiores as consideradas no presente trabalho.

Palavras-chave: Lignina, compósitos, fibras vegetais, bagaço de cana-de-açúcar, matriz fenólica.

\section{Introdução}

\section{Lignina em Resinas Fenólicas}

A lignina é encontrada em muitas plantas, conferindo rigidez à parede das células dos vegetais, atuando como agente permanente de ligação entre elas. Sua constituição em todas as plantas não é necessariamente uniforme com relação à estrutura química ou à morfologia. Portanto, não deve ser considerada como uma substância química única mas sim como uma classe de materiais correlatos ${ }^{[1,2]}$, podendo ser dividida em duas categorias: ligninas guaiacila e ligninas guaiacila-siringila. Ligninas guaiacila contêm principalmente unidades guaiacila, enquanto ligninas guaiacila-siringila contêm quantidades aproximadamente iguais de unidades guaiacila e siringila. Os dois tipos de lignina contêm ainda pequenas proporções de unidades $p$-hidroxifenila: ${ }^{[1]}$

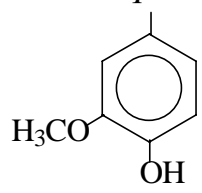

(1)

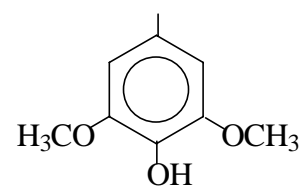

(2)

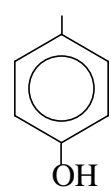

(3)
Figura 1. Unidades presentes na lignina: (1) guaiacila, (2) siringila, (3) p-hidroxifenila.

A lignina pode ser utilizada para substituir parcialmente o fenol em resinas fenólicas, pois em sua complexa estrutura estão presentes anéis aromáticos do tipo fenólico.

O interesse em substituir o fenol por lignina devese principalmente ao fato de ele ser um derivado do petróleo, uma matéria-prima não renovável, enquanto 
a lignina é obtida a partir de matéria-prima renovável como a madeira e o bagaço de cana-de-açúcar.

A lignina extraída do bagaço de cana-de-açúcar tem um maior número de centros ativos frente ao formaldeído do que a lignina extraída da madeira. Isso está ligado ao fato de a cana-de-açúcar pertencer à classe de plantas anuais e, nessas, a lignina presente contém uma proporção maior de anéis aromáticos do tipo $p$-hidroxifenila, do que outras plantas como Pinus e Eucalyptus ${ }^{[3]}$.

A lignina do bagaço de cana já foi utilizada na substituição parcial do fenol em resinas fenólicas, visando à obtenção de adesivos para madeira ${ }^{[4]}$, de moldados $^{[5],[6]}$ e de espumas fenólicas ${ }^{[7]}$.

\section{Lignina e fibras de bagaço de cana-de-açúcar em compósitos}

Várias resinas termoplásticas e termofixas têm sido utilizadas como matrizes em compósitos. As resinas termofixas mais utilizadas em compósitos de alto desempenho são as fenólicas, epóxis, bismaleimidas, poliamidas. Essas resinas exibem excelente resistência a solventes assim como a altas temperaturas. Estima-se que mais de três quartos de todas as matrizes de compósitos poliméricos sejam constituídas por polímeros termofixos ${ }^{[8]}$.

Quando se utiliza um resol, esse pode ser curado termicamente ou com a adição de um catalisador. Os resóis curados termicamente são os preferidos para sistemas reforçados com fibras de carbono, vidro e aramida, com a finalidade de obtenção de compósitos FST ("Flame-Smoke-Toxicity") para aplicações em painéis interiores e pisos de aeronaves. Os resóis curados por ácido são úteis para uso em moldagem por transferência (RTM - "Resin Transfer Molding") ou processos de pultrusão para produtos FST. Os resóis curados em meio alcalino são usados principalmente em compostos moldados (SMC-"Sheet Molding Compound") a partir de placas ${ }^{[9,10]}$.

A busca de tecnologia voltada para a preservação do ambiente e a utilização de matéria-prima proveniente de fontes renováveis têm motivado centros de pesquisa do mundo todo a estudar a utilização de fibras naturais como reforço para matrizes poliméricas ${ }^{[11]}$.

As vantagens do uso de fibras naturais sobre as tradicionais fibras de vidro, como reforço em compósitos, são: biodegradabilidade, baixo custo, baixa densidade, boa tenacidade, boas propriedades térmicas, baixo conteúdo energético e uso reduzido de instrumentos para o seu tratamento ou processamento ${ }^{[12]}$.
O bagaço de cana é atualmente o resíduo produzido em maior escala na agroindústria brasileira, com sobras anuais estimadas em torno de 60 milhões de toneladas. Estudos realizados demonstram ser possível satisfazer a demanda energética das usinas açucareiras com praticamente a metade do bagaço produzida anualmente, possibilitando o emprego do restante em mais de quarenta aplicações diferentes ${ }^{[3]}$.

O presente trabalho faz parte de um amplo projeto que visa: utilização do bagaço de cana-de-açúcar como reforço em matrizes termofixas; utilização da lignina extraída dessa fibra vegetal como substituta parcial do fenol em resóis; utilização da celulose isolada dessa matéria-prima na obtenção de derivados ${ }^{[6,7,13-19]}$.

\section{Experimental}

\section{Pré-polímero - Síntese}

Para a síntese de pré-polímeros do tipo resol, formaldeído (solução 37\%, Synth) foi adicionado a uma solução de fenol (Synth) em KOH (Synth) na proporção 1,38 : 1,00:0,06 em massa, respectivamente, com agitação mecânica. Após $90 \mathrm{~min}$ sob refluxo $\left(70^{\circ} \mathrm{C}\right)$, a solução foi resfriada até a temperatura ambiente, sendo adicionado $\mathrm{HCl}$ até a neutralização. A água presente foi, então, eliminada sob pressão reduzida.

Nas sínteses em que fenol foi parcialmente substituído por lignina ( $40 \%$ em massa; lignina extraída do bagaço-de-cana de açúcar pelo processo organossolve, utilizando-se como solvente acetona em meio ácido, gentilmente cedida pela Indústria DEDINI, PiracicabaSP), em uma primeira etapa formaldeído foi adicionado a uma solução de lignina em $\mathrm{KOH}$ (pH 9), sendo a solução mantida sob refluxo durante $60 \mathrm{~min}$, a fim de que grupos hidroximetila $\left(-\mathrm{CH}_{2} \mathrm{OH}\right)$ fossem introduzidos nos anéis fenólicos da lignina. Na sequência, fenol e formaldeído foram adicionados, seguindo o procedimento acima descrito para o pré-polímero fenólico. A proporção dos reagentes foi a mesma já citada, com a diferença de que $40 \%$ (em massa) do fenol foi substituído por lignina.

\section{Reação de entrecruzamento}

Resorcinol (10\% em massa) foi adicionado ao prépolímero, permanecendo a mistura sob agitação mecânica durante $30 \mathrm{~min}$ a $50^{\circ} \mathrm{C}$, sendo na sequência vertida sobre um molde metálico $(220,0$ X 99,5 X 5,0 
$\mathrm{mm}$, contendo cera de carnaúba como agente desmoldante), o qual foi submetido à pressão de 50 $\mathrm{kgf} / \mathrm{cm}^{2}$. A primeira etapa da reação de cura ocorreu a $75^{\circ} \mathrm{C}(60 \mathrm{~min})$ e a segunda, a $85^{\circ} \mathrm{C}(120 \mathrm{~min})$.

Os compósitos foram preparados usando-se fibras de bagaço de cana-de-açúcar $(1,5 \mathrm{~cm} ; 30,40,50,60$ e $70 \%$ (v/v) com relação à matriz; distribuição aleatória) como agente de reforço, previamente lavadas com água $\left(60^{\circ} \mathrm{C}\right)$ e submetidas à extração com cicloexano/etanol (50/50, v/v) em soxhlet, com o objetivo de extrair material inorgânico e cera presentes nas fibras. Resorcinol (10\% em massa) foi adicionado e a mistura foi submetida à agitação mecânica (30 min, $50^{\circ} \mathrm{C}$ ), a fim de impregnar a fibra com o prépolímero, e, na sequência, vertida sobre o molde. Para estes compósitos, a segunda etapa de cura $\left(85^{\circ} \mathrm{C}\right)$ ocorreu em $180 \mathrm{~min}$, tempo maior que o utilizado para o termofixo (foi observado que em $120 \mathrm{~min}$ a cura ocorreu em pequena extensão para os compósitos).

\section{Caracterização}

As amostras foram caracterizadas por:

- Calorimetria exploratória diferencial -DSC (Netzch DSC 200, atmosfera dinâmica de ar com fluxo de $20 \mathrm{~mL} / \mathrm{min}$, taxa de aquecimento $10^{\circ} \mathrm{C} /$ min, massa das amostras: 6,000-7,500 mg, cápsula de Al selada) e Termogravimetria -TG (Netzch TG 209, atmosfera dinâmica de ar, fluxo de $20 \mathrm{~mL} / \mathrm{min}, 10^{\circ} \mathrm{C} / \mathrm{min}, 6,000-7,500 \mathrm{mg}$ ): para a fibra de bagaço de cana-de-açúcar, lignina, pré-polímeros e termofixos fenólico e ligninafenol, compósitos com 30 e $70 \%$ de fibra.

- Análise mecânica termodinâmica - DMTA (DuPont, $1 \mathrm{~Hz}$, solicitação: flexão, $10^{\circ} \mathrm{C} / \mathrm{min}$ ): para termofixos fenólico e lignina-fenol e para compósitos.
- Resistência ao Impacto Charpy (Norma DIN 53453, temperatura ambiente, velocidade de impacto de $4 \mathrm{~m} / \mathrm{s}$, energia incidente de $15 \mathrm{~J}$, dez corpos de prova de cada amostra): para termofixos fenólico e lignina-fenol e para compósitos. Os resultados apresentados correspondem à média das medidas obtidas para cada amostra.

- Dureza - Shore D (ABNT NBR7456, temperatura ambiente, cinco medidas para cada amostra): para termofixos fenólico e lignina-fenol e para compósitos. Os resultados apresentados correspondem à média das medidas obtidas para cada amostra.

\section{Resultados e Discussão}

\section{Termogravimetria (TG)}

Observa-se que a fibra de bagaço perde água (Tabela 1, Figura 2) e depois se mantém estável até aproximadamente $225^{\circ} \mathrm{C}$ (a variação de perda de massa entre 100 e $200^{\circ} \mathrm{C}$ é pequena: de 8,1 para $8,8 \%$ ). Podese, portanto, considerar como limite máximo de aplicação da fibra (isoladamente) uma temperatura em torno de $200^{\circ} \mathrm{C}$. A lignina apresenta uma perda de massa menor que a da fibra até $200^{\circ} \mathrm{C}(7,5 \%$ vs $8,8 \%)$, e apresenta uma perda de massa maior que a da fibra quando se considera a variação de perda no intervalo de $100-200^{\circ} \mathrm{C}$, sendo $0,7 \%$ a da fibra e $4 \%$ a da lignina. Deve-se salientar que essa lignina analisada corresponde a uma fração extraída da fibra. Na fibra, a lignina nativa (chamada de protolignina) corresponde a uma estrutura altamente entrecruzada e com estabilidade térmica diferente da que é extraída.

Os estudos desenvolvidos nas últimas três décadas

Tabela 1. Perda de massa (cumulativa) dos polímeros termofixos e compósitos em diversas temperaturas

\begin{tabular}{lcccc}
\hline \multicolumn{1}{c}{ Material } & $\mathbf{T}=\mathbf{1 0 0}^{\circ} \mathbf{C}$ & $\mathbf{T}=\mathbf{2 0 0}{ }^{\circ} \mathbf{C}$ & $\mathbf{T}=\mathbf{3 0 0}^{\circ} \mathbf{C}$ & $\mathbf{T}=\mathbf{4 0 0}^{\circ} \mathbf{C}$ \\
\hline Termofixo Fenólico & $0,9 \%$ & $5,4 \%$ & $9,7 \%$ & $13,5 \%$ \\
Compósito 30\% Fibra & $3,1 \%$ & $8,7 \%$ & $13,4 \%$ & $22,7 \%$ \\
Compósito 70\% Fibra & $3,6 \%$ & $10,6 \%$ & $14,9 \%$ & $23 \%$ \\
Termofixo Lignina-fenol & $1,8 \%$ & $9,3 \%$ & $17,3 \%$ & $28,8 \%$ \\
Comp. Lignina-fenol 30\% Fibra & $2,9 \%$ & $9,4 \%$ & $17,4 \%$ & $28,9 \%$ \\
Comp. Lignina-fenol 70\% Fibra & $3,8 \%$ & $9,9 \%$ & $18,5 \%$ & $34,8 \%$ \\
Fibra & $8,1 \%$ & $8,8 \%$ & $36,8 \%$ & $84,9 \%$ \\
Lignina & $3,5 \%$ & $7,5 \%$ & $19,6 \%$ & $36,5 \%$ \\
\hline
\end{tabular}




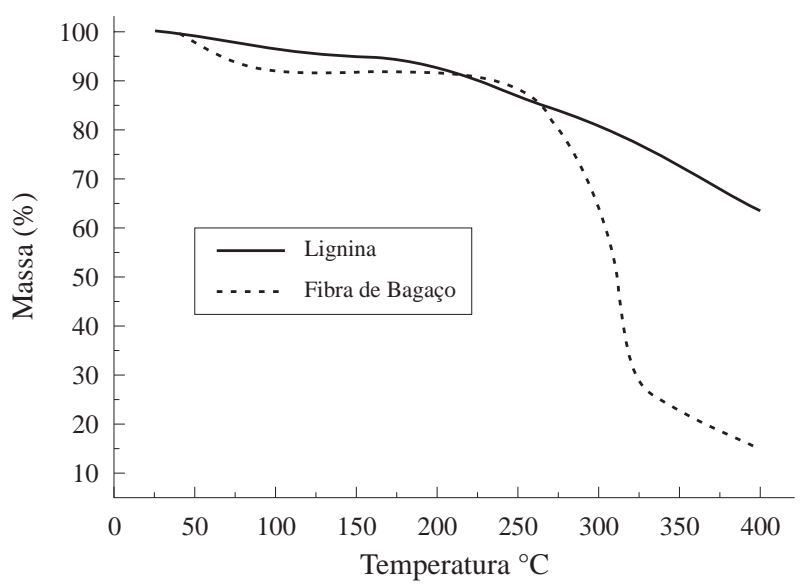

Figura 2. Curvas TG correspondentes àlignina e à fibra de bagaço de canade-açúcar (atmosfera dinâmica de ar, razão de aquecimento: $10^{\circ} \mathrm{C}$ min).

mostraram que a degradação térmica de resinas fenólicas em altas temperaturas envolve principalmente reações de oxidação, independentemente se a amostra é exposta a ar, nitrogênio, argônio ou vácuo ${ }^{[21]}$.

A temperaturas altas (em torno de $400^{\circ} \mathrm{C}$ ), em atmosfera inerte, podem ocorrer oxidações envolvendo a ponte metilênica que liga os anéis aromáticos. A reação mais simples proposta considera a participação da água liberada em etapas residuais de cura (Reação 1).

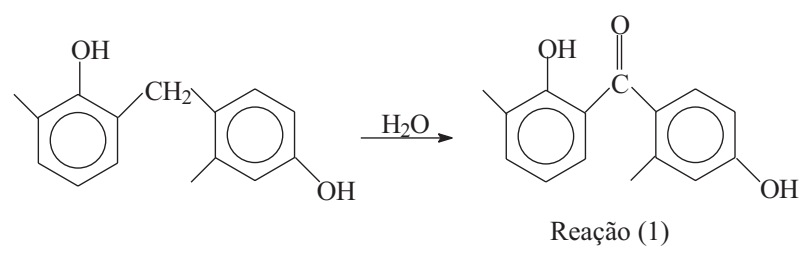

Outras reações mais complexas envolvem a quebra homolítica das ligações entre o anel e a ponte metilênica, e entre o anel e a hidroxila fenólica, gerando radicais (Reação 2 e Reação 3) ${ }^{[21]}$.

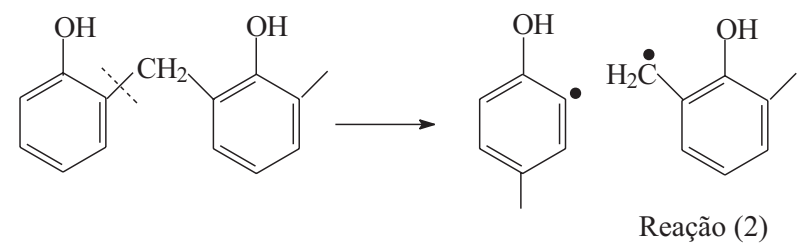<smiles></smiles>

A reação entre estas espécies, altamente reativas, pode levar a estruturas contendo grupo alcoólico (Reação 4).

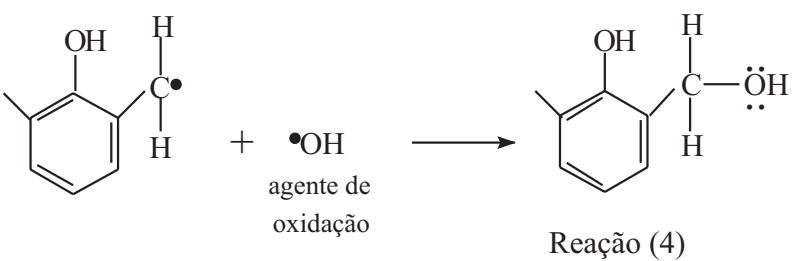

Oxidações subseqüentes deste grupo alcoólico $-\mathrm{CH}_{2} \mathrm{OH}$ levam em uma primeira etapa ao grupo aldeído, o qual facilmente se oxida para grupos carboxílicos. A descarboxilação leva à liberação de $\mathrm{CO}_{2}$ (Reação 5).

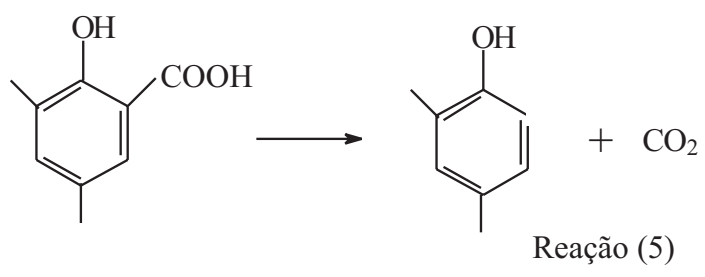

Na presença de ar, o oxigênio é o agente oxidante, levando à formação de carbonilas, similarmente à reação 1. Nessa condição a oxidação pode ocorrer a temperaturas mais baixas (em torno de $300^{\circ} \mathrm{C}$ ).

A vaporização dos subprodutos voláteis gerados nas reações citadas anteriormente (e em muitas outras que podem ocorrer) leva à perda de massa. Além disso, normalmente as resinas não estão totalmente entrecruzadas, podendo ocorrer reações de condensação residual, com perda de água ${ }^{[22]}$.<smiles></smiles>

Ainda em torno de $300^{\circ} \mathrm{C}$, pode ocorrer uma condensação envolvendo as duas hidroxilas fenólicas, formando ligações do tipo difenil-éter (Reação 7) ${ }^{[21]}$.

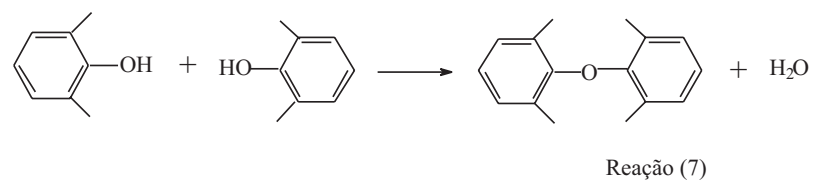

A ocorrência das reações descritas acima faz com que, a partir de determinada temperatura, possa ocorrer perda de massa continuamente, como mostram as figuras a seguir (Figuras 3 e 4), correspondentes às curvas TG de termofixos e compósitos. Essas curvas são similares às outras obtidas para os demais compósitos.

Analisando-se as curvas TG dos polímeros e compósitos, pode-se observar uma perda de massa ini- 


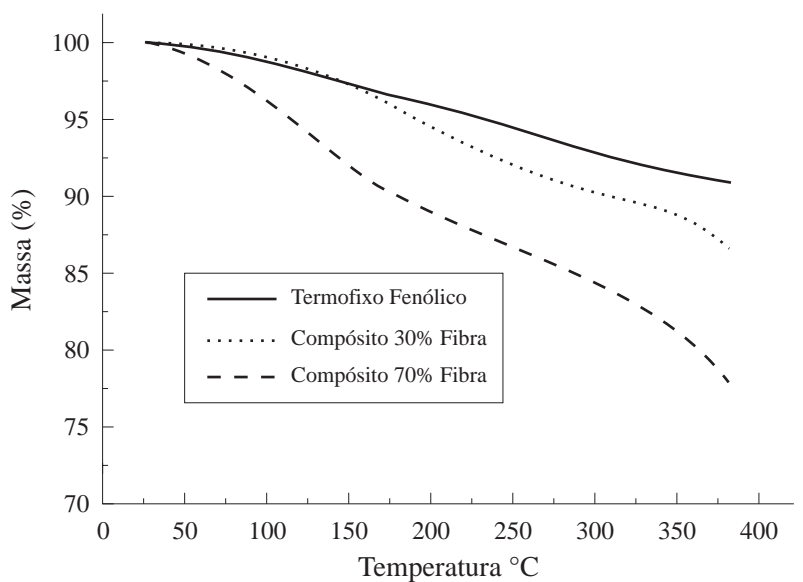

Figura 3. Curvas TG correspondentes ao polímero termofixo fenólico e compósitos contendo $30 \%$ e $70 \%$ de fibra (atmosfera dinâmica de ar, razão de aquecimento: $10^{\circ} \mathrm{C} \mathrm{min).}$

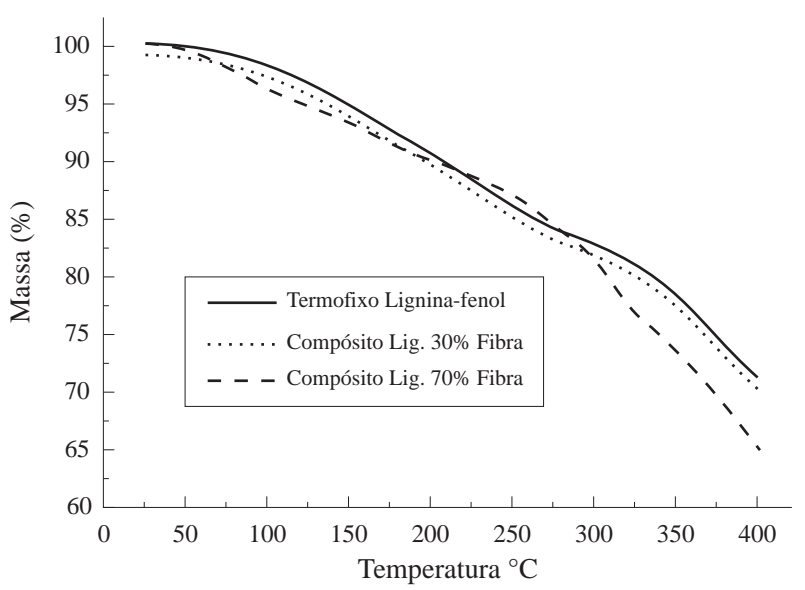

Figura 4. Curvas TG correspondentes ao polímero termofixo ligninafenol e compósitos contendo $30 \%$ e $70 \%$ de fibra (atmosfera dinâmica de ar, razão de aquecimento: $10^{\circ} \mathrm{C} \mathrm{min).}$

cial de $0,9 \%$ a $3,8 \%$ até $100^{\circ} \mathrm{C}$, que possivelmente corresponde à volatilização de moléculas pequenas, como a água, presente devido à umidade contida nos polímeros e nas fibras dos compósitos. A introdução de fibras vegetais aumenta o teor de umidade nos compósitos, pois as fibras vegetais são higroscópicas e a inclusão destas numa matriz menos higroscópica acaba gerando um produto com teor de umidade mais elevado.

Entre 100 e $200^{\circ} \mathrm{C}$, observa-se para o termofixo fenólico uma variação de $4,5 \%$. Como será discutido posteriormente na análise de $\mathrm{DSC}$, em torno de $150^{\circ} \mathrm{C}$ ocorre uma etapa de cura residual, com liberação de água. A vaporização da água deve estar provocando esta alteração. A presença de fibra aumenta esta variação para 5,6\% (compósito com $30 \%$ de fibra) e $7,0 \%$ (para o compósito contendo $70 \%$ de fibra). A fibra isoladamente sofre uma variação de $0,7 \%$, a qual no caso dos compósitos deve somar-se à da matriz.
Analisando-se ainda o intervalo entre 100 e $200^{\circ} \mathrm{C}$; nota-se que quando a lignina está presente na matriz (polímero termofixo lignina-fenol, compósitos lignina-fenol $30 \%$ e $70 \%$ de fibra) a variação da massa diminui conforme aumenta a proporção de fibra. A presença de lignina pode facilitar a ocorrência de reações entre matriz e fibra, o que poderia levar a uma eventual diminuição de grupos polares, diminuindo assim a perda de massa. Deve-se, no entanto, ressaltar que a variação é pequena (polímero ou matriz lignina-fenol: 7,5\%; compósito contendo $30 \%$ de fibra: 6,5\%; compósito contendo $70 \%$ de fibra: $6,1 \%$ ), e que o acima postulado necessita de investigações mais detalhadas para confirmação.

No intervalo entre 200 e $300^{\circ} \mathrm{C}$, o termofixo fenólico e os compósitos têm uma variação de massa em torno de $4,5 \%$, enquanto que a fibra isoladamente tem uma variação de $28 \%$ neste mesmo intervalo. Observa-se, portanto, que a estabilidade térmica das fibras nos compósitos é superior a da fibra isolada [compósito $70 \%$ de fibra (Fig.3) e fibra (Fig. 2)]. Isso pode ser uma indicação que, nessa faixa de temperatura, intensificam-se as reações entre matriz e fibras, tornando estas últimas mais estáveis termicamente. A degradação da celulose nessa faixa de temperatura envolve os grupos hidroxila, e se esses se envolveram em reações com a matriz, estarão menos disponíveis para a reação de degradação, aumentando a estabilidade da fibra. Para o intervalo de $300-400^{\circ} \mathrm{C}$, observa-se um efeito similar ao acima descrito.

Para o termofixo lignina-fenol e os respectivos compósitos tem-se também uma indicação de que a fibra manifesta maior estabilidade no compósito do que isoladamente. O termofixo e os compósitos apresentam curvas semelhantes (Figura 4).

Na temperatura de $400^{\circ} \mathrm{C}$, ocorre perda de massa mais acentuada para todas as amostras, o que, para os polímeros e compósitos, pode estar relacionado ao início de degradação da cadeia polimérica.

O termofixo lignina-fenol e os respectivos compósitos revelam uma maior perda de massa na temperatura de $400^{\circ} \mathrm{C}$ comparando-se com os outros fenólicos, fato que provavelmente ocorre devido à fragmentação de ligações interunidades da lignina. A decomposição ou condensação de anéis aromáticos ocorrem entre 400 e $500^{\circ} \mathrm{C}^{[20]}$.

\section{Calorimetria Exploratória Diferencial}

As reações que foram discutidas anteriormente (1 a 7) resultam em picos endotérmicos ou exotérmicos. 


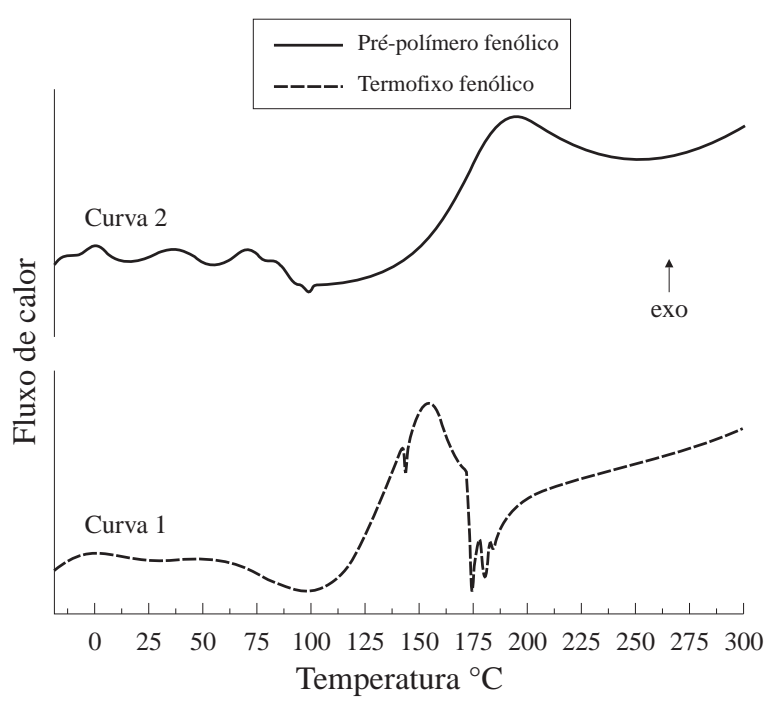

Figura 5. Curvas DSC do pré-polímero e termofixo fenólico (atmosfera dinâmica de ar, razão de aquecimento: $10^{\circ} \mathrm{C} \mathrm{min}$ ).

A cura de resinas fenólicas foi por muito tempo relatada como sendo um processo exotérmico. No entanto, muita controvérsia tem surgido na literatura $^{[5,6]}$ envolvendo resinas fenólicas com e sem lignina. Na realidade, em uma reação de condensação que envolve a liberação de moléculas pequenas, como a água, o pico endotérmico resultante da vaporização desta pode mascarar um eventual processo exotérmico.

A curva DSC (Figura 5, Curva 1) para o prépolímero fenólico contendo $10 \%$ de resorcinol mostra um pico exotérmico em torno de $154^{\circ} \mathrm{C}$ e picos endotérmicos acima deste. Esse pico, provavelmente corresponde a outra etapa de cura, seguida de vaporização da água.

Para o termofixo fenólico (Figura 5, Curva 2), o pico exotérmico aparece em torno de $199^{\circ} \mathrm{C}$. Essa amostra já se encontra no estado sólido e, portanto, a reação que leva à condensação (cura residual) tornase mais difícil, necessitando de maior energia que no caso do pré-polímero (líquido viscoso).

$\mathrm{O}$ pico endotérmico que aparece em torno de $250^{\circ} \mathrm{C}$ pode estar relacionado a mais de um processo. Nesta região ocorre perda de massa, podendo indicar vaporização de voláteis formados em reações de condensação do tipo descrito na reação 3.7, ou reações de oxidação pelo $\mathrm{O}_{2}$ do ar, do tipo descrito na reação 3.1, que em etapas subsequentes pode levar à formação de $\mathrm{CO}_{2}$.

Uma amostra do termofixo fenólico foi submetida a uma etapa de pós-cura (em estufa a $150^{\circ} \mathrm{C}, 1: 30$ h) e posteriormente foi submetida à análise de DSC. Observa-se que o pico exotérmico referente à cura

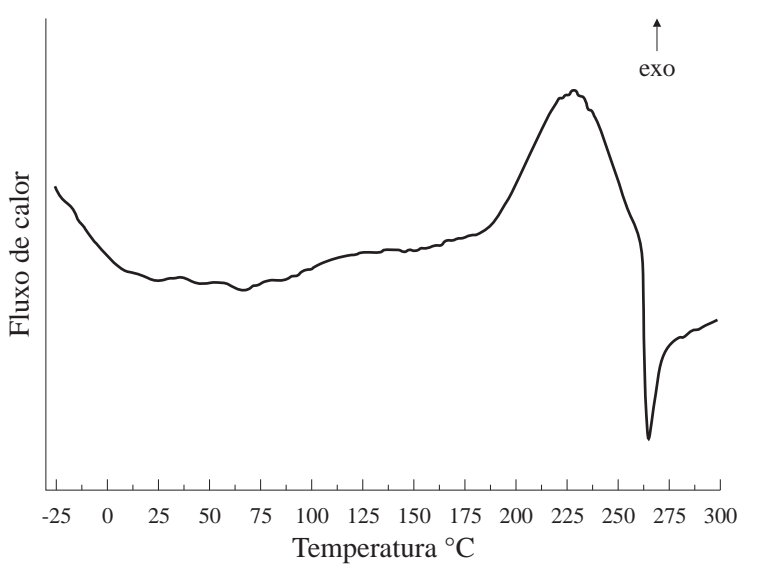

Figura 6. Curva DSC (após a pós-cura) do polímero fenólico (atmosfera dinâmica de ar, razão de aquecimento: $10^{\circ} \mathrm{C} \mathrm{min).}$

residual (Figura 6) aparece deslocado para maior temperatura (em torno de $228^{\circ} \mathrm{C}$ ), porque a reação tornase ainda mais difícil. O pico endotérmico também aparece deslocado para maior temperatura.

A curva correspondente ao DSC da fibra (não mostrado) apresenta um largo pico endotérmico, podendo-se observar que esta curva incorpora dois processos: um que ocorre em torno de $152^{\circ} \mathrm{C}$ e outro, em torno de $260^{\circ} \mathrm{C}$. A curva termogravimétrica referente à fibra não apresenta perda de massa em torno de $150^{\circ} \mathrm{C}$, portanto este pico não deve corresponder à vaporização de moléculas pequenas. Como a fibra passou por processos de extração, é pouco provável que corresponda à fusão de oligômeros de lignina ou de celulose. Este pico pode corresponder à ruptura de ligações hidrogênio inter e intramoleculares, provavelmente envolvendo a estrutura celulósica ou, ainda, ser conseqüente de acomodações que envolvem as

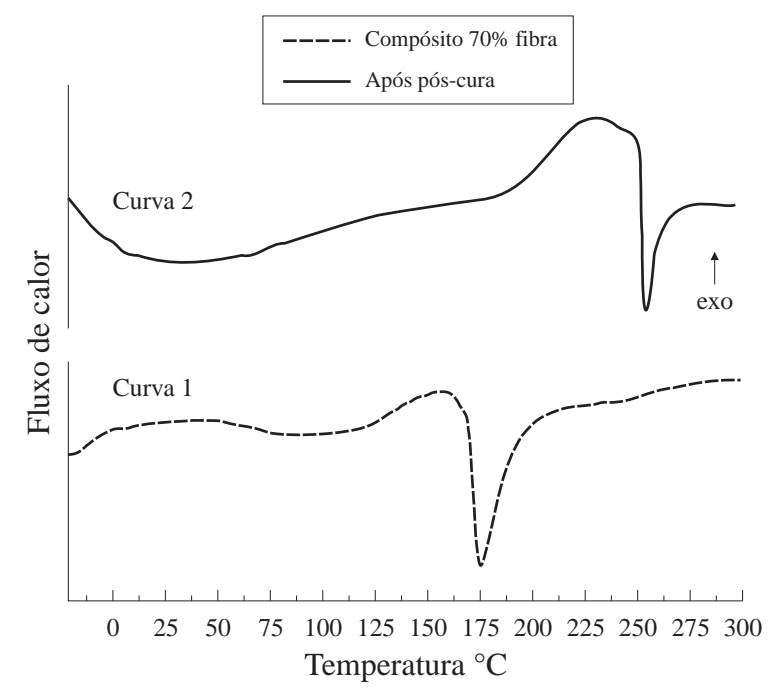

Figura 7. Curvas DSC do compósito contendo $70 \%$ de fibra, e do mesmo submetido à pós-cura (atmosfera dinâmica de ar, razão de aquecimento: $10^{\circ} \mathrm{C} \mathrm{min).}$ 
regiões cristalinas da celulose e que provocam alterações no tipo de rede cristalina. Observa-se ainda uma alteração na curva em torno de $260^{\circ} \mathrm{C}$, possivelmente relacionada à degradação da celulose, que pode ocorrer em torno desta temperatura, concordando com a curva termogravimétrica relacionada.

Quando o compósito é submetido a uma pós-cura (em estufa a $150^{\circ} \mathrm{C}, 1: 30 \mathrm{~h}$ ), a curva DSC correspondente a esta amostra (Figura 7, Curva 2) não apresenta mais os picos endotérmicos relacionados à fibra. Nesse caso, a modificação da fibra, assim como a cura residual, ocorreu antes de a amostra ser submetida à análise (ou seja, durante a etapa de pós-cura). Embora esta amostra tenha passado por outro estágio de entrecruzamento, isto não significa que o mesmo tenha levado à cura total e o pico exotérmico observado a $233^{\circ} \mathrm{C}$ pode corresponder a outra reação deste tipo, ou ainda, como a análise é feita na presença de ar, processos oxidativos podem começar a ocorrer.

As amostras contendo lignina (pré-polímeros, termofixo e compósitos) apresentaram curvas DSC semelhantes às acima descritas, com pequenas variações nas temperaturas em que os picos aparecem.

\section{Resistência ao Impacto}

A resistência ao impacto do termofixo fenólico (Figura 8) encontra-se dentro do intervalo citado na literatura $\left(3,5 \text { a } 6,0 \mathrm{~kJ} / \mathrm{m}^{2}\right)^{[23]}$. Observa-se que os compósitos contendo 40\%, 50\%, 70\% de fibra (Tabela 2, Figura 8) mostraram uma maior resistência ao impacto com relação à matriz, indicando que a energia do choque em alta velocidade foi absorvida pela matriz e distribuída às fibras. Os compósitos com

Tabela 2. Média dos resultados de Resistência ao Impacto do termofixo fenólico e termofixo lignina-fenol e seus compósitos

\begin{tabular}{lc}
\hline \multicolumn{1}{c}{ Material } & $\begin{array}{c}\text { Resistência ao Impacto } \\
(\mathbf{k J} / \mathbf{m} 2)\end{array}$ \\
\hline Termofixo Fenólico & $6,0 \pm 0,22$ \\
Compósito 30\% Fibra & $5,7 \pm 0,37$ \\
Compósito 40\% Fibra & $7,7 \pm 0,30$ \\
Compósito 50\% Fibra & $7,8 \pm 0,34$ \\
Compósito 70\% Fibra & $8,6 \pm 0,35$ \\
Termofixo Lignina-Fenol & $5,8 \pm 0,31$ \\
Comp. Lignina-Fenol 30\% Fibra & $6,2 \pm 0,20$ \\
Comp. Lignina-Fenol 40\% Fibra & $7,7 \pm 0,22$ \\
Comp. Lignina-Fenol 50\% Fibra & $8,2 \pm 0,21$ \\
Comp. Lignina-Fenol 70\% Fibra & $8,5 \pm 0,22$ \\
\hline
\end{tabular}

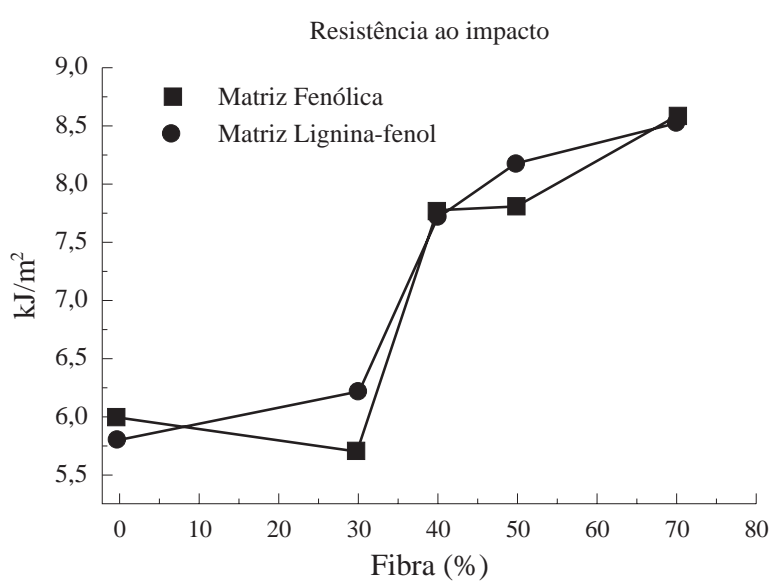

Figura 8. Variação da Resistência ao Impacto do polímero termofixo fenólico e termofixo lignina-fenol e seus compósitos com diversas porcentagens de fibras.

matriz lignina-fenol mostraram um comportamento semelhante ao discutido para matriz fenólica, indicando que a substituição parcial de fenol por lignina não prejudica esta propriedade.

\section{Dureza Shore D}

A dureza Shore D diminui conforme aumenta o conteúdo de fibra (Figura 9). As fibras vegetais são higroscópicas; portanto, conforme aumenta o conteúdo das mesmas, aumenta o teor de umidade do material. A presença de moléculas de água na superfície tem um efeito plastificante na superfície do material. Nesse sentido, como no ensaio é avaliada a dureza da superfície e não a do interior do material, os resultados obtidos não necessariamente estão indicando que a presença das fibras diminui a resistência mecânica à penetração de um corpo, mas podem estar relacionados à maior higroscopicidade do compósito. A me-

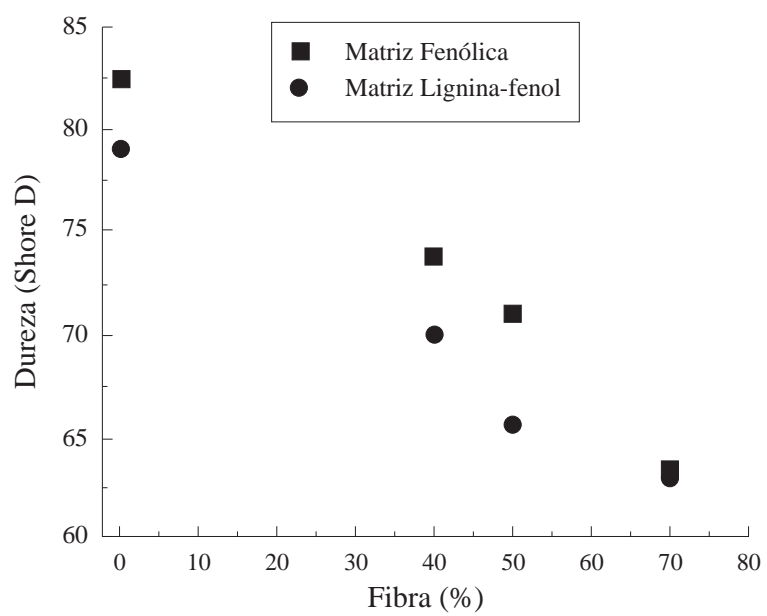

Figura 9. Variação da Dureza Shore D do polímero termofixo fenólico e termofixo lignina-fenol e seus compósitos com diversas porcentagens de fibras. 
nor dureza dos compósitos com lignina também reforça essa possibilidade, já que a presença de diversos grupos polares neste "macromonômero" pode aumentar a capacidade de absorção de umidade.

\section{DMTA}

Para esta análise, assim como para as demais que utilizaram corpos de prova, estes foram cortados diretamente da placa obtida na moldagem por compressão, usando-se o molde descrito na parte experimental. Foi considerado que, desta forma, os resultados revelariam melhor a performance dos compósitos em uma eventual aplicação. A realização da cura em moldes com dimensões solicitadas pelo ensaio (dimensões reduzidas) pode fazer que certas propriedades, como módulo de elasticidade, sejam maximizadas, não refletindo o comportamento do material quando em aplicação, o que normalmente requer dimensões consideravelmente superiores àquelas de um corpo de prova.

Deve-se salientar que esta análise é feita em condições dinâmicas, enquanto as outras propriedades mecânicas foram avaliadas em ensaios estáticos, ou seja, não existe necessariamente, uma correlação direta entre os resultados obtidos usando-se diferentes técnicas. Pode-se esperar uma maior sensibilidade das medidas de DMTA, no sentido de refletir as interações na interface do compósito, devido à sua característica dinâmica.

Do ponto de vista macroscópico, para se aproveitar todo o potencial do material de reforço, é necessário que haja boa adesão na interface fibra-matriz, durante a aplicação ${ }^{[24]}$. Um reforço pode aumentar a resistência ao impacto e diminuir o módulo elástico da matriz, porém, o ideal seria haver um compromisso entre estas duas propriedades ${ }^{[25]}$.

O módulo de elasticidade do compósito depende da fração em volume da fibra e da matriz. Como o módulo da fibra é normalmente superior ao da matriz, conforme aumenta a fração de fibra, o módulo do compósito deveria aumentar. No entanto, outros fatores devem ser considerados: comprimento da fibra (fibras muito curtas não terão muitos pontos de contato com a matriz, podendo se desprender; fibras muito longas tornam mais difícil uma distribuição homogênea); intensidade de adesão na interface ${ }^{[26,27]}$.

A Figura 10 mostra o comportamento dos compósitos com matriz lignina-fenol. Curvas similares são obtidas para compósitos com matriz fenólica. Pode-se observar que os compósitos têm módulo me-

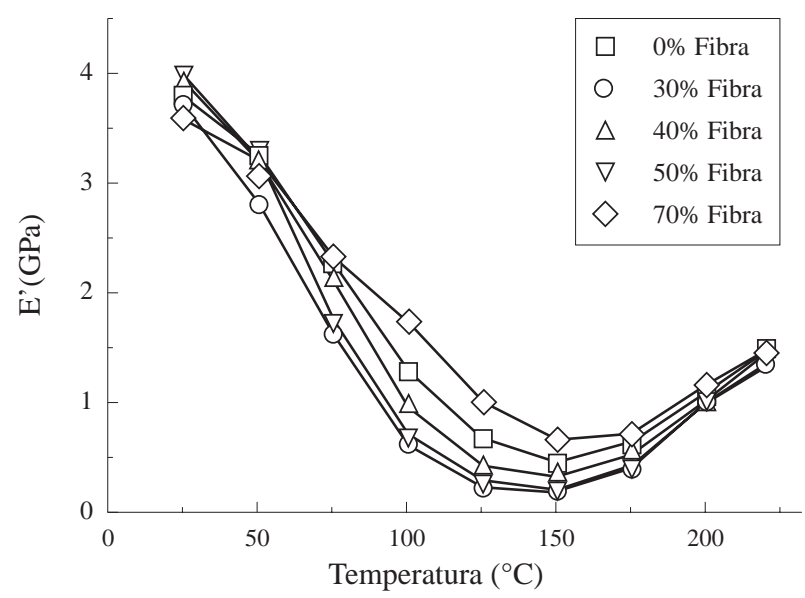

Figura 10. E' (módulo de elasticidade) versus T para compósitos com matriz lignina-fenol.

nor que o da matriz, em todo o intervalo de temperatura. A higroscopicidade da fibra vegetal leva a uma maior absorção de água, o que pode estar promovendo um efeito plastificante. Ainda, os fatores acima indicados podem estar operando: o comprimento das fibras não foi adequado, a adesão na interface fibramatriz não foi intensa.

No entanto, na avaliação dessa propriedade, os seguintes fatores normalmente operantes em compósitos devem também ser destacados, já que os compósitos apresentaram módulo inferior ao da matriz, em todo o intervalo de temperatura:

- Em conseqüência do processamento, a superfície do compósito pode ter um excesso da matriz, comparando-se com a parte interna, ou seja, uma menor quantidade de fibras na superfície. Como em testes de flexão o esforço máximo deve ocorrer na superfície, as propriedades da matriz (que normalmente tem menor módulo que a fibra) são realçadas, podendo mascarar a propriedade do material como um todo ${ }^{[28]}$. Com a finalidade de se avaliar a influência deste efeito nos valores de módulo obtidos, futuramente tentar-se-á eliminar a superfície contendo excesso do termofixo, através de lixamento da mesma, considerando para medida a parte do material onde a distribuição de fibras é mais uniforme.

- A matriz pode ter sido submetida à uma tensão devido a diferença entre o seu coeficiente de expansão térmica e o da fibra, o que pode provocar alterações consideráveis no módulo ${ }^{[28]}$.

Acima de $150^{\circ} \mathrm{C}$, observa-se um acréscimo no módulo, o qual é conseqüência de uma segunda etapa de cura (que torna o material mais rígido), conforme confirmado por resultados de TG (perda de massa 
neste intervalo de temperatura) e de DSC, que mostra um pico endotérmico (reação seguida de vaporização de água) nesta região, o qual desaparece após submeter amostra a $150^{\circ} \mathrm{C}$ por $90 \mathrm{~min}$.

\section{Conclusões}

Os resultados obtidos mostram a viabilidade técnica da substituição de fenol por lignina em matrizes fenólicas de compósitos.

Os estudos termogravimétricos indicaram que a estabilidade térmica dos compósitos reduziu com o aumento do teor de fibras de bagaço de cana-de-açúcar.

A resistência ao impacto é uma propriedade que merece destaque, devido à importância da mesma para materiais poliméricos. Observou-se que a resistência aumenta com a proporção de fibra utilizada, sendo que resultados similares são encontrados para os dois tipos de matriz. No entanto, aplicações em que esta propriedade é importante requisitam valores mais altos que os encontrados.

O teor de umidade aumenta conforme aumenta a proporção de fibra no compósito, e esse acréscimo é ainda mais significativo quando a lignina está presente ${ }^{[16]}$. Tal comportamento é indesejável, pois traz prejuízo a diversas propriedades, conforme já discutido.

O conjunto de resultados obtidos indica que várias modificações devem ser feitas, podendo-se destacar: modificação da fibra por meio de reações químicas, com o intuito de minimizar a absorção de água e incrementar a adesão fibra-matriz (introduzindo cadeias apolares, com grupos funcionais no final da cadeia, os quais permitirão o desenvolvimento de ligações químicas entre fibra e matriz, durante a etapa de cura); diversificação do comprimento das fibras vegetais; realização de reações de entrecruzamento considerando etapas de cura em temperaturas acima daquelas utilizadas no presente trabalho, a fim de verificar-se um possível efeito desse parâmetro sobre as propriedades mecânicas. Desta forma, pretende-se alcançar propriedades compatíveis com às exigidas para aplicações industriais.

\section{Agradecimentos}

À Fundação de Amparo à Pesquisa do Estado de São Paulo (FAPESP) e ao Conselho Nacional de Desenvolvimento Científico e Tecnológico (CNPq).

\section{Referências bibliográficas}

1. Glasser, W.G.; Kelley S.S. - "Lignin. Encyclopedia of Polymer Science and Engineering", John

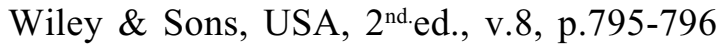
(1985).

2. Paturau, J.M. - "By Products of the Cane Sugar Industry", Elsevier Science Publishers, Amsterdam, The Netherlands, $3^{\text {rd }}$ ed., v.11, p.39 (1989).

3. Piccolo, R.S.J. - "Síntese e Caracterização de Resinas Lignina-Fenol-Formaldeído", Dissertação de Mestrado, IFQSC-USP, São Carlos, p. 1112 (1993).

4. Ysbrandy, R.E.; Sanderson, R.D.; Gerischer, G.F.R. - Holzforschung, 46 (3), 253-256 (1992).

5. Piccolo, R.S.J.; Santos, F.; Frollini, E. J.Macrom.Sci.-Pure and Applied Chemistry, A34(1), 153-164 (1997).

6. Pimenta, M.J.A.; Frollini, E. - "Lignin: Utilization as a "Macromonomer"in the Synthesis of Phenolic Type Resin", Anais Assoc. Bras. Quím., 46(1), 43-49 (1997).

7. Carvalho, G.; Frollini, E.; Santos, W.N. - J. Appl. Polym. Sci., 62, 13, 2281-2285 (1996).

8. Mattews, F. L.; Rawlings, R.D. - "Composite Materials: Engineering and Science”, Chapman \& Hall, Great Britain, 1'ed., p.168-169 (1994).

9. Pilato, L.A.; Michno, M.J. - "Advanced Composite Materials", Springer Verlag Heidelberg, Berlin, Germany, p.20-23 (1994).

10. Mano, E.B. - "Polímeros como Materiais de Engenharia"; Edgard Blucher Ltda, São Paulo, p.115-129 (1991).

11.Mattoso, L.H.C.; Fragalle, E.P. - Uso de Fibras Vegetais na Indústria Automobilística: Necessidade Ecológica, Oportunidade para o Brasil, Polímeros Ciência e Tecnologia, p.9-13 (1996).

12. Narayan, R. - Polimeric Materials from Agricultural Feedstocks. Polymers from Agricultural Coproducts; Ed. Fishman, Friedman, Huang, American Chemical Society, Washington; p.26 (1994).

13. Regiani, A M., Frollini, E., - Synthesis of Cellulose Derivatives Under Homogeneous Solution 
Conditions, $5^{\text {th }}$ Latin American and $3^{\text {rd }}$ Ibero American Polymer Symposium, Mar del Plata, Argentina, p.201-202 (1996).

14. Frollini, E.; Piccolo, R.S.J.; Cerne, J. L.;.De Groote, R. M. C. J. Macromolecular Science Pure and Applied Chemistry, (A31), 1215-1217, (1994).

15. Martinez, C. M. F.; Frollini, E.; Campana Fo. S.P. - Propriedades Absorventes dos Produtos da Carboxi-metilação de Polpa Etanol-água de Medula de Bagaço de Cana-de-açúcar, Polímeros - Ciência e Tecnologia, p.1243 (1997).

16. Paiva, J. M. F., Trindade, W. G., Frollini, E. - Sugar Cane Bagasse Fiber as Reinforcement in Phenolic Matrix-Composite; Proceedings of Second International Symposium on Natural Polymers and Composites, Ed. L. H. C. Mattoso, E. Frollini, A. L. Leão; Atibaia, SP, Brazil, p.143-148 (1998).

17. Marson, G.; Regiani, A. M.; Frollini E.; Seoud, O. A. - Cellulose Esterification in Homogeneous Medium, J. Polym. Sci. Chemistry, in press, (1999).

18. Curvello, A. A.; Frollini, E.; Campana, S. P. "Organosolv Delignification of Lignocellulosic Materials: Preparation and Characterization of Lignin and Cellulose Derivatives, Lignocellulosics - Plastics Composites. Ed. A. L. Leão, F. X. Carvalho, E. Frollini, p.163-180 (1997).
19. Picollo, R. S. J.; Frollini, E.; Curvelo, A. A. S. "Transformacion de Lignina em Produtos de Alto Valor Agregado", Ed. Cyted D, p.212-219 (1997).

20. Rohella, R. S.; Sahoo, N.; Paul, S.C.; Choudhury, S.; Chakravortty, V. - Thermochimica Acta, 287, 131-138 (1996).

21. Costa, L.; Montelera, R. di; Carmino, G.; Weil, E. D.; Pearce, E.M. - Polymer Degradation and Stability, 56, 23-25 (1997).

22. Chang, C.; Tackett, J. R. - Thermochimica Acta, 192, 181-190 (1991).

23. Simitzis, J.; Sfyrakis, J. - J. Appl. Polym. Sci., 54, 2091-2099 (1994).

24. Jinen, E. - Thermoplastics-Composites. Science and Technology, 33, 19-33 (1988).

25. Stenzenberger, H. D. - Thermosetting Matrix Systems and their Influence for Carbon Fibre Reinforcement. Carbon Fibres and their Composites, 95-116 (1985).

26.Van Krevelen, D. W. - "Properties of Polymers", Elsevier Science Publishers, $3^{\text {rd }}$ ed., p.38 (1990).

27. Hage, E. G. - "Macromolecules", Plenum Press, $2^{\text {nd }}$ ed., p.455-457, p.1173-1179 (1984).

28. Sichina, W. J. - "Low Composite Modulus Values", Publicação Du Pont, p. 2:38-2:41 (1986).

Recebido em: 18/02/99

Aprovado em: 10/06/99 